\section{Comparison of Acid and Alkaline Hydrogen- Bromine Fuel Cell Systems}

\author{
Trung Van Nguyen ${ }^{\mathrm{a}^{*}}$, Venkata Yarlagadda ${ }^{\mathrm{a}}$, \\ Guangyu Lin ${ }^{\mathrm{b}}$, Guoming Weng ${ }^{\mathrm{c}}$, Vanessa $\mathrm{Li}^{\mathrm{c}}$, \\ and Kwong-Yu Chan ${ }^{\mathrm{c}}$ \\ ${ }^{\mathrm{a}}$ Department of Chemical \& Petroleum Engineering \\ The University of Kansas \\ Lawrence, KS, USA \\ ${ }^{\mathrm{b}} \mathrm{TVN}$ Systems, Inc. \\ Lawrence, KS, USA \\ ${ }^{c}$ Department of Chemistry \\ The University of Hong Kong \\ Hong Kong SAR, China \\ *Corresponding Author: cptvn@ku.edu
}

\begin{abstract}
The hydrogen bromine $\left(\mathrm{H}_{2}-\mathrm{Br}_{2}\right)$ fuel cell system is an attractive system for electrical energy storage because of its high round-trip conversion efficiency, high power density capability, and anticipated low costs.
\end{abstract}

The hydrogen-bromine fuel cell system can be operated in the acid or alkaline modes. The charge and discharge electrode reactions in an acid $\mathrm{H}_{2}-\mathrm{Br}_{2}$ fuel cell system are as follows:

\section{Bromine Electrode:}

$$
\mathrm{Br}_{2(\mathrm{aq})}+2 \mathrm{e}-\underset{\text { Charge }}{\stackrel{\text { Discharge }}{\leftarrow}} 2 \mathrm{Br}_{(\mathrm{aq})}^{-}, \boldsymbol{E}^{o}=+\mathbf{1 . 0 9} \mathbf{~ V}
$$

Hydrogen Electrode:

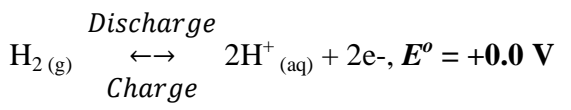

The $\mathrm{H}^{+}$ions migrate from the hydrogen side across a proton conducting membrane to the bromine side during discharge to combine with the $\mathrm{Br}^{-}$ions to form hydrobromic acid.

\section{Overall Reaction:}

$$
\mathrm{H}_{2(\mathrm{~g})}+\mathrm{Br}_{2(\mathrm{aq})} \underset{\text { Charge }}{\stackrel{\text { Discharge }}{\leftrightarrow}} 2 \mathrm{HBr}_{(\mathrm{aq})}, \boldsymbol{E}^{o}=\mathbf{+ 1 . 0 9} \mathbf{V}
$$

The charge and discharge electrode reactions in an alkaline $\mathrm{H}_{2}-\mathrm{Br}_{2}$ fuel cell system are as follows:

\section{Bromine Electrode:}

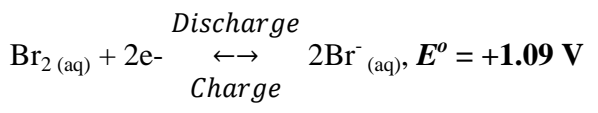

\section{Hydrogen Electrode:}

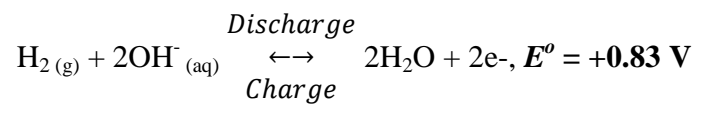

The cations (e.g., $\mathrm{K}^{+}$), associated with the $\mathrm{OH}^{-}$ ions, migrate from the hydrogen electrode across a cation $\left(\mathrm{K}^{+}\right)$conducting membrane to the bromine side and combine with the $\mathrm{Br}^{-}$ions to form $\mathrm{KBr}$ as shown in the overall reaction.

\section{Overall Reaction:}

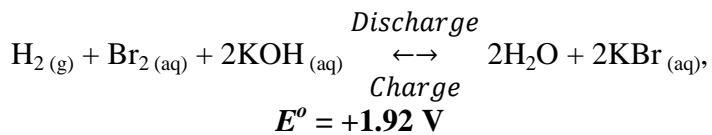

Based on the reactions shown above the alkaline system offers a higher cell voltage, which is an advantage because of potentially higher power output. However, the hydrogen reactions in this system are two-phase reactions involving gaseous hydrogen and liquid-phase hydroxide ion reactants and will require more complex electrode structure and fuel cell design. The other advantages of this system include the fact that non-noble catalysts can be used for the hydrogen reactions and lower corrosiveness.

This presentation will discuss the advantages and disadvantages of the alkaline and acid $\mathrm{H}_{2-}$ $\mathrm{Br}_{2}$ fuel cell systems and compare the discharge and charge performance of both systems.

\section{Acknowledgements}

This work was funded in part by the National Science Foundation through grant number EFRI1038234 and the Research Grants Council of Hong Kong through a General Research Fund (GRF HKU 700210P). A Visiting Professorship to Trung Nguyen was provided by the Initiative on Clean Energy and Environment (ICEE), University of Hong Kong. 